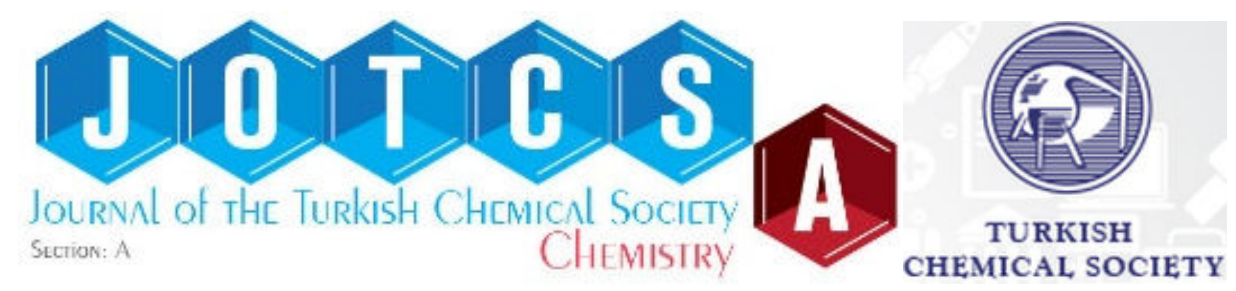

(This article was presented to the 28th National Chemistry Congress and submitted to JOTCSA as a full manuscript)

\title{
Electrorheological Properties of Biodegradable Chitosan/Expanded Perlite Composites
}

\author{
Mehmet Cabuk ${ }^{1 *}$ \\ ${ }^{1}$ Süleyman Demirel University, 32260, Isparta, Turkey.
}

\begin{abstract}
In this study, chitosan (CS)/expanded perlite (EP) composites with different chitosan fractions $(10 \%, 20 \%$ and $50 \%$ ) were prepared by absorbing chitosan into porous networks of expanded perlite, as a new hybrid smart electrorheological (ER) material. Structural and morphological characterizations of the composites were carried out by FTIR and SEM-EDS techniques. Also, apparent density, particle size, and conductivity of the CS/EP composites were determined. Finally, the effects of electric field strength $(E)$, shear rate, shear stress, and temperature onto ER behavior of the CS/EP/silicone oil (SO) system were investigated. The CS/EP/SO ER system showed reversible ER activity when subjected to $E$ by showing shear thinning non-Newtonian viscoelastic behavior. The yield stress value reached to $1250 \mathrm{~Pa}$ under $E=3 \mathrm{kV} / \mathrm{mm}$ for CS/EP3 composite.
\end{abstract}

Keywords: Electrorheological fluids, expanded perlite, chitosan, composite, silicone oil, yield stress.

Submitted: July 1, 2016. Revised: August 15, 2016. Accepted: August 22, 2016.

Cite this: Cabuk M. Electrorheological Properties of Biodegradable Chitosan/Expanded Perlite Composites. Journal of the Turkish Chemical Society, Section A: Chemistry. $2016 ; 3(3): 119-32$.

DOI: $10.18596 /$ jotcsa.26894.

*Corresponding author. E-mail: mehmetcabuk@sdu.edu.tr, Tel: +902465112739; Fax: +902465112744 . 


\section{INTRODUCTION}

Electrorheological (ER) fluids are composed of semiconducting or polarizable particles dispersed in a non-conducting liquid and regarded as smart materials because their flow behaviors can be tuned by externally applied $E$. These smart particles are polarized and formed fibrous structures when subjected to $E$ by increasing their viscosities reversibly due to the interparticle interactions. ER fluids have been extensively studied because of their potential applications in many industrial areas such as control systems, human muscle stimulators, robotic arms, seismic controlling frame structures, and photonic crystals [13].

Natural polymers such as cellulose, starch, and chitosan have been widely used in ER

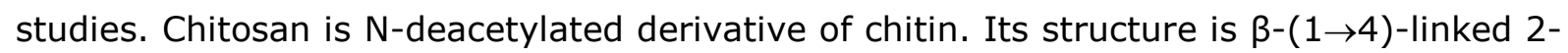
amino-2-deoxy-D-glucose and 2-acetamido-2-deoxy-D-glucose. Chitosan obtained from the shells of crustaceans like crabs and shrimps. The main properties of chitosan are biodegradability, solubility in organic acids, chemical inertness, biocompatibility, low density and low cost [4]. On the other hand, its low mechanical and thermal stability is a barrier for chitosan's applications. Preparation of chitosan/clay composite is one of the attractive techniques to improve its weak features [5]. ER active properties of Chitosan/Silicone oil suspension was reported in the literature and attributed to the presence of polarizable amino polar groups onto chitosan backbone [6]. Chitosan adipate which is a chitosan derivative, was used as ER material [7].

About $70 \%$ of the world's known perlite reserves are located in Turkey. Perlite is a naturally occurring dense glassy volcanic rock which consists mainly of fused sodium, potassium, aluminum silicate (greater than $70 \%$ ) and $3-5 \%$ water. When it is heated at temperatures in the range of $850-1100{ }^{\circ} \mathrm{C}$, it expands $4-35$ times of its original volume and is named as 'expanded perlite' [8]. Expanded perlite (EP) is an excellent thermal and acoustical insulator, resists fire, and is an ultralight weight material. EP is chemically inert in many environmental areas. Therefore, they are excellent filter aids and fillers in various processes and materials [9]. 
The benefit of using biodegradable CS/EP composites as a dispersed phase in ER applications is important both from industrial and environmental point of views. The aim of the present study was to reveal the preparation, characterization, and investigation of the ER properties of biodegradable CS/EP composites which have not hitherto been reported in the literature. The composite structures were characterized via FTIR, and SEMEDS analyzes. Then, CS/EP dispersions were prepared in SO at $10 \%$ volume fraction and the effects of $E$, shear rate and temperature on ER performance of these dispersions were investigated.

\section{MATERIALS AND METHODS}

\section{Materials}

The EP particles were obtained from AKPER Company (Çankırı, Turkey). The chemical composition of the EP is given in Table 1 . CS, $\overline{M w}=3.0 \times 10^{5} \mathrm{gmol}^{-1}$ and with $82 \%$ degree of deacetylation, was purchased from Aldrich with analytical grade. SO ( $\eta=1 \mathrm{~Pa}, \rho=$ $0.965 \mathrm{~g} \mathrm{~cm}^{-3}, \varepsilon=2.61$ at $25^{\circ} \mathrm{C}$ ) was obtained from Aldrich and used in ER measurements. $\mathrm{NaOH}$, acetic acid (HAC) and all the other chemicals were purchased from E. Merck and used as received.

\section{Synthesis of CS/EP composites}

Before the experiments, EP samples were washed with distilled water to remove any impurities. Then the EP particles were ground milled (Retsch MM400, Germany) and vacuum dried before subjecting to particle size measurements. For the synthesis of CS/EP composites; $5 \mathrm{~g}$ EP was stirred in $300 \mathrm{~mL}$ distilled water for $2 \mathrm{~h}$. Then, CS $(0.5 \mathrm{~g})$ was dissolved $(10 \%(w / w)$ of $E P)$ in $100 \mathrm{~mL}$ of $2 \%(w / w)$ HAc solution and added into the EP/water dispersion at room temperature. The white dispersion was stirred at room temperature for $4 \mathrm{~h}$. And then, the reaction mixture was treated with $1 \mathrm{M}$ aqueous $\mathrm{NaOH}$ solution by dropwise addition of $\mathrm{NaOH}$ to provide the precipitation of $\mathrm{CS}$ chains $(\mathrm{pH}=7-8)$. $\mathrm{CS}$ biopolymer is only soluble in acidic medium of $\mathrm{pH}$ below 6.5 . Then the precipitates were washed with distilled water until the particles were neutral and dried in a vacuum oven at $60{ }^{\circ} \mathrm{C}$ for $48 \mathrm{~h}$. The same method was applied for the other CS fractions ( $20 \%$ and $50 \%$ ). Synthesized CS/EP composites containing 10, 20 and 50 wt.\% of CS were obtained nearly $88 \%$ yield and coded as CS/EP1, CS/EP2 and CS/EP3, respectively. Thus, three different CS/EP composites were prepared and used in characterization and ER studies. 
Table 1. Chemical composition of perlite [10].

\begin{tabular}{cc}
\hline Component & \% \\
\hline $\mathrm{SiO}_{2}$ & $72-76$ \\
$\mathrm{Al}_{2} \mathrm{O}_{3}$ & $11-17$ \\
$\mathrm{~K}_{2} \mathrm{O}$ & $4-5$ \\
$\mathrm{Na}_{2} \mathrm{O}$ & $3-4$ \\
$\mathrm{CaO}$ & $0.5-2$ \\
$\mathrm{MgO}$ & $0.1-0.5$ \\
$\mathrm{Fe}_{2} \mathrm{O}_{3}$ & $0.5-1.5$ \\
$\mathrm{TiO}_{2}$ & $0.03-0.2$ \\
$\mathrm{MnO}_{2}$ & $0.03-0.1$ \\
$\mathrm{SO}_{3}$ & $0-0.2$ \\
$\mathrm{H}_{2} \mathrm{O}$ & $2-7$ \\
\hline
\end{tabular}

\section{Characterizations}

Perkin Elmer Spectrometer BX model (England) was used to record the FTIR spectra as $\mathrm{KBr}$ discs. The surface morphology of the samples was performed using a scanning electron microscope (SEM) with an energy-dispersive X-ray spectrometer (EDS) (SEM/EDS, XL 30S FEG, Phillips). The particle sizes of the composites were performed via a Malvern Mastersizer $\mathrm{E}$, version $1.2 \mathrm{~b}$ particle size analyzer by dispersing in distilled water and stirring at $20^{\circ} \mathrm{C}$. The samples were turned into pellets and these pellets were used for apparent density and electrical conductivity measurements. Conductivities of the samples were measured via four-probe technique and calculated with the equation of $\sigma=d / A R$, where $\sigma$ is conductivity, $d$ is the thickness, $A$ is the surface area, and $R$ is the resistance of the samples.

ER studies: Dispersions of the samples were prepared in $\mathrm{SO}$ at a constant volume fraction $(\varphi=10 \% \mathrm{~V} / \mathrm{V})$. To investigate the ER properties of the suspensions, Thermo-Haake RS600 parallel plate torque Electro-Rheometer (Germany) was used with a $35 \mathrm{~mm}$ plate to plate geometry by altering the shear rate between $1-1000 \mathrm{~s}^{-1}$ and keeping the gap between the upper and lower plates as $1.0 \mathrm{~mm}$. To determine the electric field viscosity, electric field was created in the fluid perpendicular to the plates, and the rotor was forced to rotate. The voltage used in the ER experiments was supplied by a 0-12.5 kV (with $0.5 \mathrm{kV}$ increments) dc external electric field generator (FUG electronics, Germany) The CS/EP/SO dispersions were mechanically stirred against sedimentation before each measurement. 


\section{RESULTS AND DISCUSSION}

\section{Characterization results}

Figure 1 presents the FTIR spectra of CS/EP composites (inset shows CS). CS shows distinctive peaks of typical saccharide absorptions as mentioned in the literature [11]. The broad peak at $3200-3600 \mathrm{~cm}^{-1}$ is attributed to $\mathrm{O}-\mathrm{H}$ stretching and $\mathrm{N}-\mathrm{H}$ stretching, the peak at 2900 is due to $\mathrm{C}-\mathrm{H}$ stretching, the peak at $1700 \mathrm{~cm}^{-1}$ is due to $\mathrm{C}=\mathrm{O}$ stretching; also, the broad peak at $1050 \mathrm{~cm}^{-1}$ is attributed to $\mathrm{C}-\mathrm{C}$ stretching of saccharide structure of chitosan. EP shows typical clay peaks [9]. The peaks at $3430 \mathrm{~cm}^{-1}, 1050 \mathrm{~cm}^{-1}$ and $800-$ $530 \mathrm{~cm}^{-1}$ are assigned to stretching vibrations of structural hydroxyl (-OH), Si-O stretching vibrations and stretching vibrations of $\mathrm{Al}-\mathrm{O}$, respectively. As shown in Figure 1, The CS/EP1, CS/EP2 and CS/EP3 composites showed all the expected characteristic peaks arising from the CS and EP structures. It is shown that there are differences in the intensities and values of peaks. It can be attributed to electrostatic interactions between the polycationic CS and negatively charged EP units.

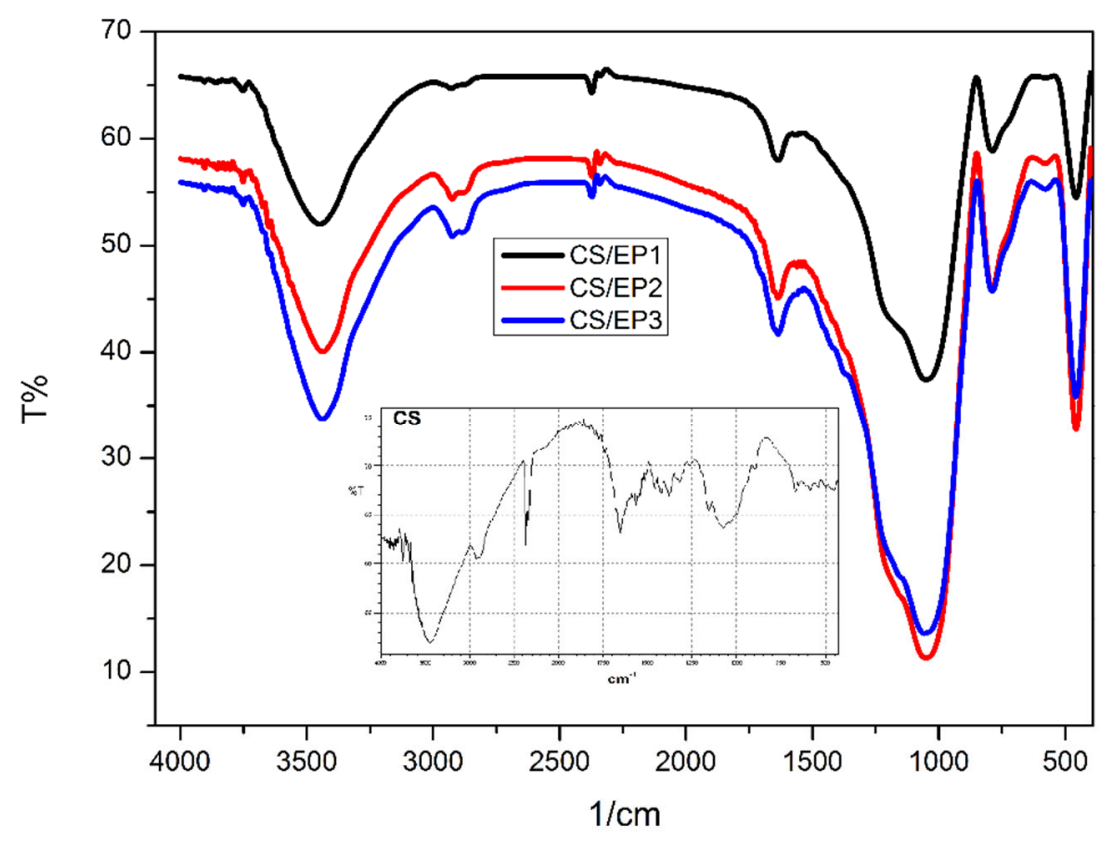

Figure 1. FTIR spectra of CS/EP composites. Inset shows CS.

Figure 2(a-c) shows the SEM-EDS images of CS/EP composites. It was observed that CS/EP composites have splintery and porous morphology. With the increasing CS percentage in the composite structure, EP particles were more surrounded by CS biopolymer and then the morphology was turned to less porous particle structure, as expected. Note that SEM shows the shape of the surfaces, while Energy Dispersive Spectroscopy (EDS) gives the composition of the surfaces. The elemental analysis data of the EDS analysis was given in 
Table 2. According to EDS results, the presence of both CS and EP components in the composite structures were proved. The CS structure was characterized with $\mathrm{N}$ and $\mathrm{C}$ atoms. It was observed that the percentage of these atoms increased with increasing CS content in the composite formation. The wt.\% values of $\mathrm{N}$ atoms in the CS/EP composites were found as $0.95 \%, 2.44 \%$ and $3.80 \%$ with the increasing CS content (from $10 \%$ to $20 \%$ and $50 \%$ ), respectively.

Table 2. Elemental analysis values (wt.\%) of the samples according to EDS results.

\begin{tabular}{|l|l|l|l|l|l|l|l|}
\hline Samples & $\mathbf{C}$ & $\mathbf{N}$ & $\mathbf{O}$ & $\mathbf{N a}$ & $\mathbf{A l}$ & $\mathbf{S i}$ & $\mathbf{K}$ \\
\hline CS/EP1 & 5.08 & 0.95 & 46.89 & 2.75 & 7.28 & 32.41 & 4.66 \\
\hline CS/EP2 & 13.65 & 2.44 & 45.71 & 2.36 & 6.32 & 26.13 & 3.42 \\
\hline CS/EP3 & 28.45 & 3.80 & 43.36 & 1.45 & 3.70 & 16.62 & 2.63 \\
\hline
\end{tabular}
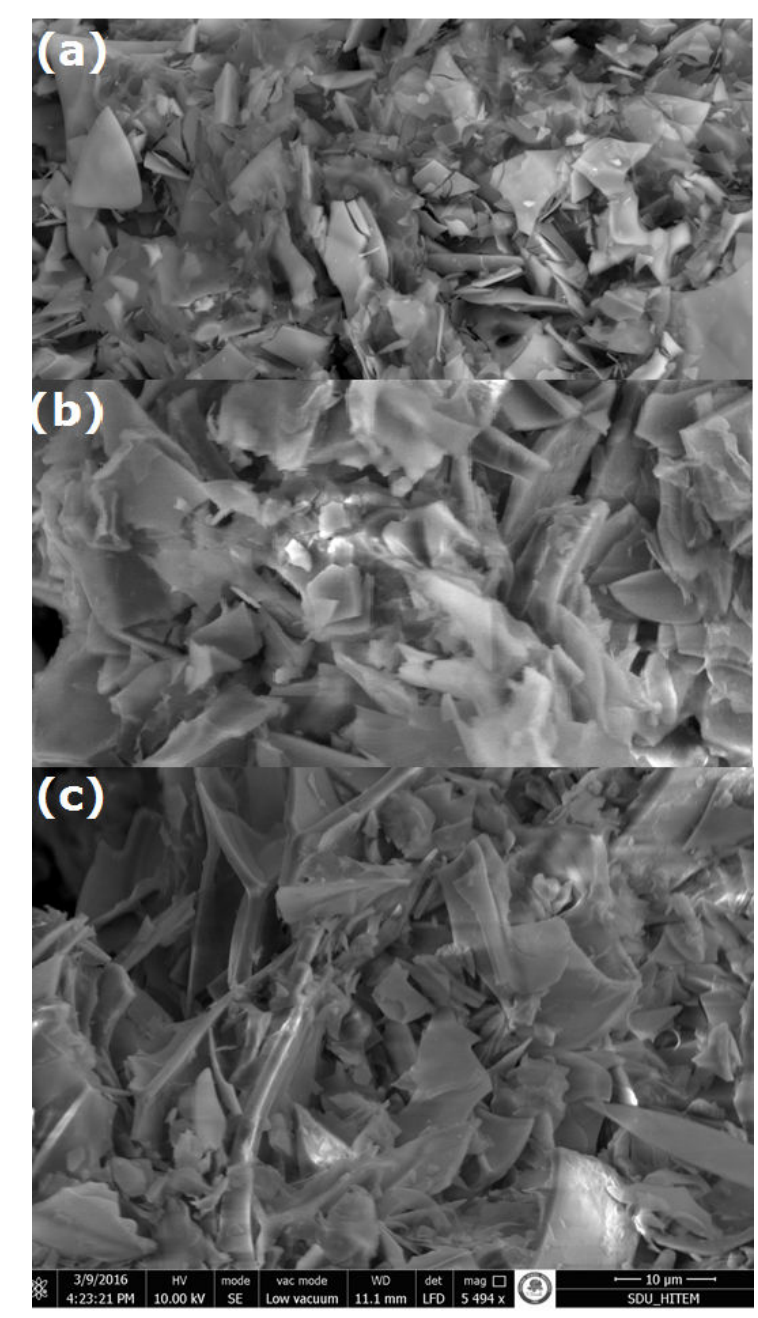

Figure 2. SEM images of a) CS/EP1, b) CS/EP2, c) CS/EP3 composites.

Hydrodynamic average particle diameters, apparent densities, and conductivities of the composites were given in Table 3. The hydrodynamic average diameters of the particles increased with increasing CS content. As expected, the hydrodynamic average particle 
sizes of the composites obtained from dynamic light scattering experiments were bigger than the ones obtained from SEM images $(\sim 10 \mu \mathrm{m})$. Densities of the composites observed to increase with increasing CS content due to the high density of the CS $\left(0.86 \mathrm{gcm}^{-3}\right)$ compared with that of EP $\left(0.44 \mathrm{gcm}^{-3}\right)$. The conductivities of the CS/EP composites were found in semiconducting range and slightly increased with increasing CS content. These characterization results of the composites are very suitable for their potential and industrial applicability as new ER materials.

Table 3. Some physical properties of the samples $\left(T=25^{\circ} \mathrm{C}\right)$.

\begin{tabular}{cccc}
\hline Samples & $\begin{array}{c}\text { Average hydrodynamic } \\
\text { diameters }(\mathbf{n m})\end{array}$ & $\begin{array}{c}\text { Electrical conductivity } \\
\left(\boldsymbol{\sigma}, \mathbf{S c m}^{-\mathbf{1}}\right)\end{array}$ & $\begin{array}{c}\text { Apparent density } \\
\left(\mathbf{p}, \mathbf{g c m}^{-3}\right)\end{array}$ \\
\hline CS/EP1 & 32 & $2.0 \times 10^{-4}$ & 0.52 \\
CS/EP2 & 37 & $2.3 \times 10^{-4}$ & 0.67 \\
CS/EP3 & 44 & $2.9 \times 10^{-4}$ & 0.80 \\
\hline
\end{tabular}

ER results: The ER properties are attributed to the chaining of micron-sized polarizable particles with applied $E$, electro-rheometer studies are conducted to observe the electric field induced viscosity change and ER behaviors of CS/EP composite dispersions, and results obtained are discussed below.

\section{ER efficiencies of the CS/EP/SO fluids}

The dependence of the viscosity on the $E$ was given in Figure 3. As shown that the viscosity of all the CS/EP composites increased with applied $E$, which confirms that the ER fluids are solid-like under $E$. It is known that CS is responsible component for the CS/EP composites to show ER effect. The viscosity values were observed to increase with rising CS content which has polarizable amino groups in the composite structure. CS enhances the particle polarization by increasing the particle surface conductivity of CS/EP composites via enhanced interfacial polarization and the attractive interactions of particles, which would lead to the enhanced ER response. ER efficiencies of the samples as a function of the composite composition were determined using eq. (1):

$$
E R_{\text {efficiency }}=\frac{\eta_{E \neq 0}-\eta_{E=0}}{\eta_{E=0}}
$$

where $\eta_{E}=0$ and $\eta_{E \neq 0}$ show the non-electric field- and electric field-induced viscosities of the dispersions, respectively. ER efficiencies of the samples were calculated from Figure 3 under constant conditions $(\varphi=10 \%, E=0-3 \mathrm{kV} / \mathrm{mm})$ and results were found as follows: $0.11<0.21<0.26$ for CS/EP1, CS/EP2 and CS/EP3 composites, respectively. As shown, the highest ER efficiency was determined for CS/EP3/SO composite dispersion which has the 
highest CS content and that is why, for the rest of the ER experiments, CS/EP3/SO ER fluid was used.

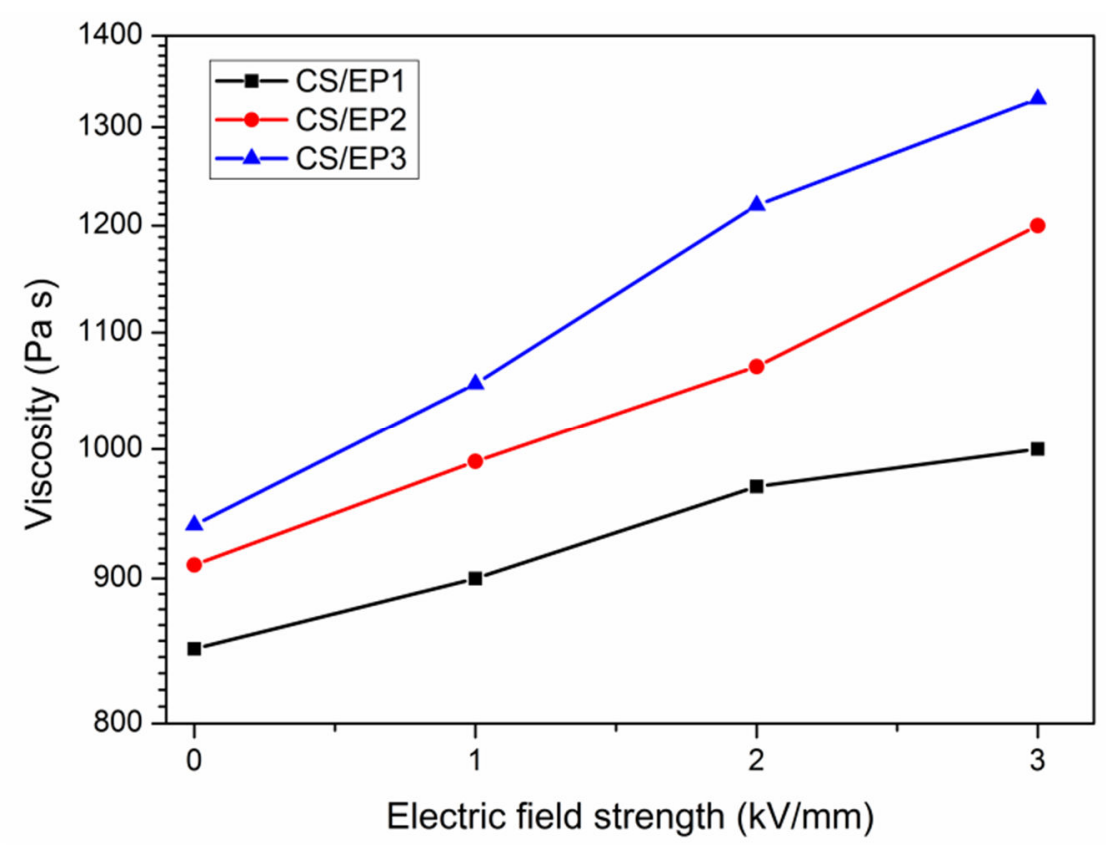

Figure 3. The effect of $E$ on viscosity. $\varphi=10 \%, T=25^{\circ} \mathrm{C}$.

\section{Effect of shear rate on viscosity}

The change of viscosity with shear rate was presented in Figure 4. Electric field induced viscosity of CS/EP3/SO ER fluid sharply decreased with increasing shear rate and showed a typical shear thinning non-Newtonian viscoelastic behavior. This behavior may be attributed to the distortion and breakage of fibrillar structures between the perlite particles. Similar behavior was reported for chitosan phosphate suspensions [12]. 


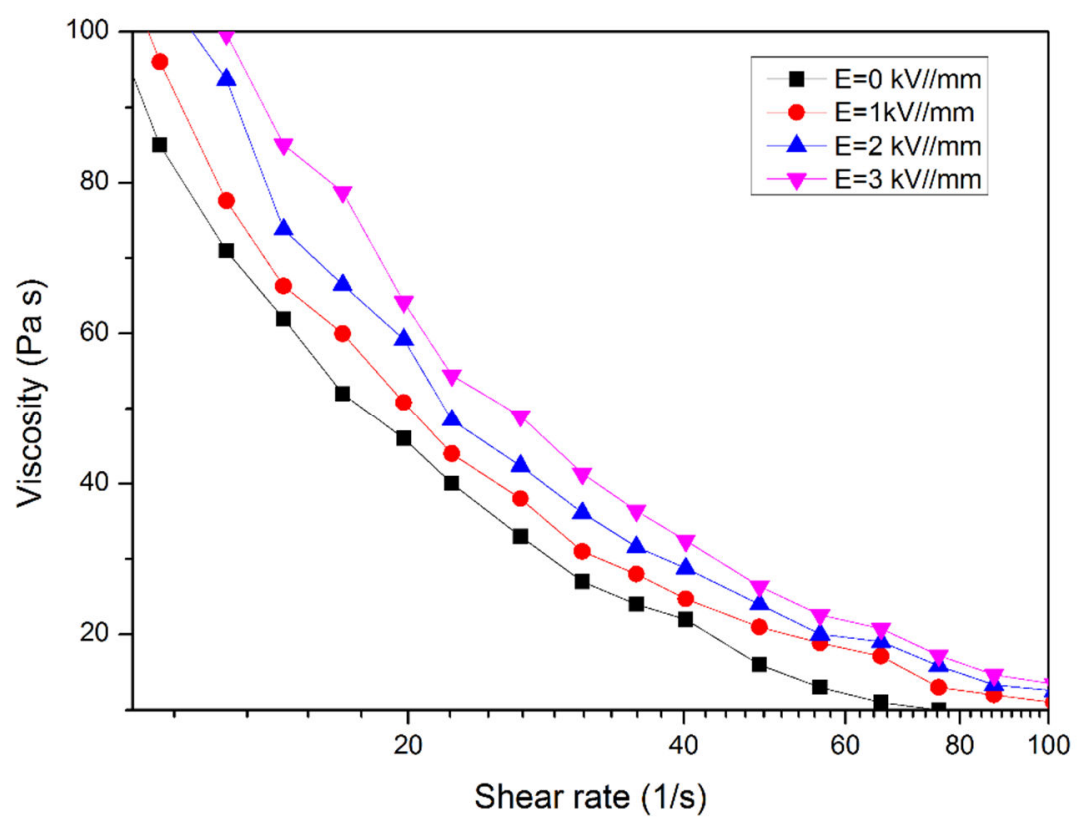

Figure 4. Change in viscosity with shear rate. $\varphi=10 \%, T=25^{\circ} \mathrm{C}$.

\section{Effect of shear rate on shear stress}

Figure 5 shows the change of shear stress with shear rate. It was observed that shear stress increased with rising shear rate and with the applied $E$, the ER fluid showed typical non-Newtonian Bingham-like flow behavior. Under an applied $E$, the curves of the samples first showed yield stresses and then wide plateau regions [13] which may be attributed to the polarization mechanism of the EP particles.

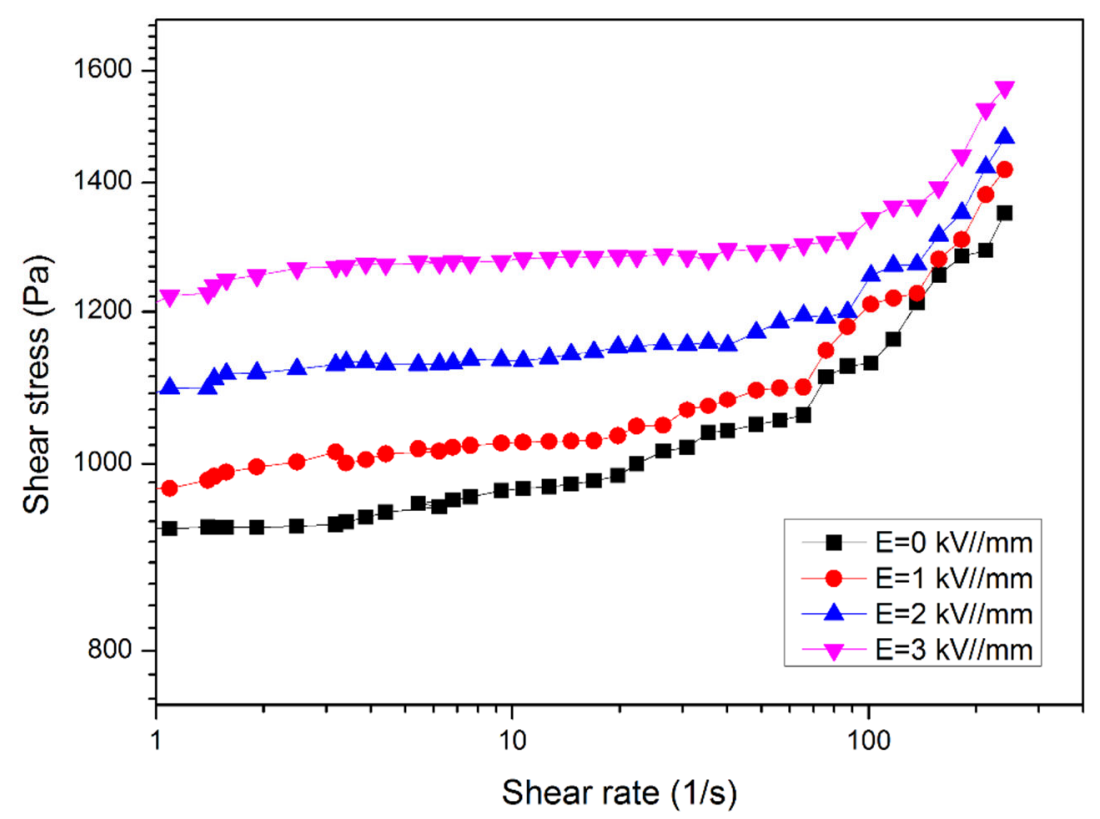

Figure 5. Change in shear stress with shear rate. $\varphi=10 \%, \mathrm{~T}=25^{\circ} \mathrm{C}$. 
Yield stress $\left(T_{y}\right)$ values of the composites were obtained from the initial slops of the shear rate-shear stress graphs [14]. The yield stress values of the CS/EP3/SO ER fluid were observed to increase with rising $E$ and the results obtained are as following: $T_{y}=1250 \mathrm{~Pa}$ $(E=3 \mathrm{kV} / \mathrm{mm})>T_{y}=1100 \mathrm{~Pa}(E=2 \mathrm{kV} / \mathrm{mm})>T_{y}=980 \mathrm{~Pa}(E=1 \mathrm{kV} / \mathrm{mm})>T_{y}=920 \mathrm{~Pa}(E$ $=0 \mathrm{kV} / \mathrm{mm}$ ). It can be attributed to the formations of stronger solid-like fibrous structures between the electrodes with the influence of dipole-dipole interactions of the semiconducting particles.

\section{Effect of temperature on shear stress}

To test whether the CS/EP3 composite shows ER weakening or loss of power between 30$80{ }^{\circ} \mathrm{C}$, shear stress measurements were carried out under $E=3 \mathrm{kV} / \mathrm{mm}$ (Figure 6). As shown, slight shear stress increments were observed with increasing temperature. The increasing temperature can be caused to the increase of polarization forces between the particles due to the increasing current density, dielectric constant and conductivity with rising temperature. Thus, the increasing polarization forces cause a stronger fibrous structure and the ER effect increases. On the other hand, the viscosity of the SO media decreases with the temperature and this may also be caused the fibrous chain formation relatively easy and thus leads to improved ER performance $[15,16]$.

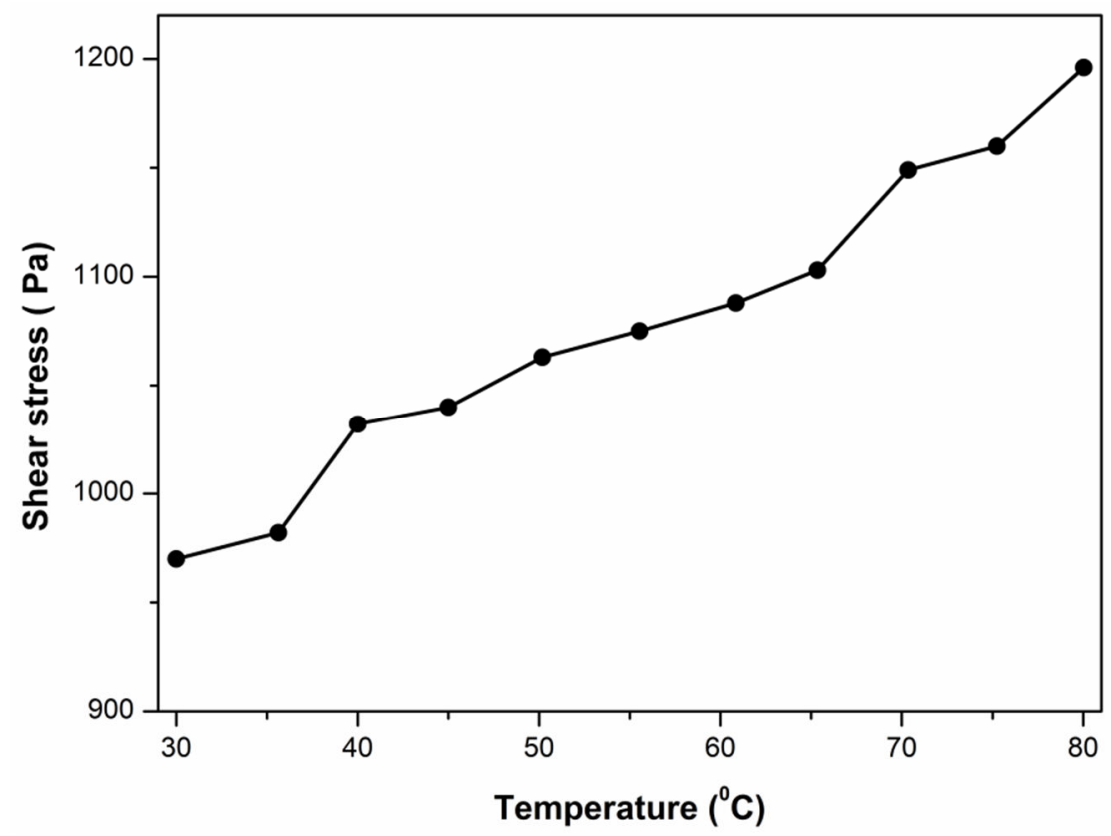

Figure 6. Change in shear stress with temperature. $\varphi=10 \%, E=3 \mathrm{kV} / \mathrm{mm}, \dot{\gamma}=0.2 \mathrm{~s}^{1-}$. 


\section{CONCLUSION}

Biodegradable CS/EP composites with different CS fractions were successfully prepared and their structures and morphologies were confirmed by FTIR and SEM-EDS analyses. Conductivities of the composites were found in semiconducting range which is suitable for ER measurements. The CS/EP/SO system were observed to sensitive to external $E$ by showing reversible viscosity enhancements. ER efficiencies and yield stresses of the ER fluids increased with increasing CS content having polar amino groups. Shear stress values of the ER fluids were slightly affected with temperature.

\section{ACKNOWLEDGMENTS}

The author thanks to Turkish Scientific and Technological Research Council, TUBITAK (Grant No: 214Z199) for the support of this work.

\section{REFERENCES}

[1] Lin, KF, Hsu CY, Huang TS, Chiu WY, Lee YH, Young TH. A novel method to prepare chitosan/montmorillonite nanocomposites. Journal of Applied Polymer Science. 2005 SEP; 98 : 2042-47. DOI: DOI: 10.1002/app.22401.

[2] Zhang WL, Liu YD, Choi HJ, Kim SG. Electrorheology of Graphene Oxide. ACS Appl. Mater. Inter. 2012 APR; 4: 2267-72. DOI: 10.1021/am300267f.

[3] Cabuk M, Yavuz M, Unal HI. Colloidal, electrorheological, and viscoelastic properties of polypyrrole-graft-chitosan biodegradable copolymer. J. Intel. Mat. Syst. Str. 2015 MAR; 26: 1799-810. DOI: $0.1177 / 1045389 \times 15577652$.

[4] Kittur FS, Prashanth KVH, Sankar KU, Tharanathan RN. Characterization of chitin, chitosan and their carboxymethyl derivatives by differential scanning calorimetry. Carbohydrate Polymers. 2002 APR; 49: 185-93. DOI: doi:10.1016/S0144-8617(01)00320-4.

[5] Hong $\mathrm{CH}$, Sung JH, Choi HJ. Effects of medium oil on electroresponsive characteristics of chitosan suspensions. Colloid and Polymer Science. 2009 MAY; 287: 583-89. DOI: 10.1007/s00396-0092006-3.

[6] Jang WH, Cho YH, Kim JW, Choi HJ, Sohn JI, Jhon MS. Electrorheological fluids based on chitosan particles. Journal of Material Science Letters. 2001; 20: 1029-31. DOI: 10.1023/A: 1010960424567. 
[7] Choi US, Park YS. Electrorheological behavior of chitosan adipicate suspension as anhydrous ER fluid. Journal of Industrial and Engineering Chemistry. 2001 JUL; 7: 281-4. DOI: $10.1016 /$ j.polymer.2005.10.133.

[8] Dogan M, Alkan M. Removal of methyl violet from aqueous solution by perlite. J. Colloid Interface Sci. 2003 OCT; 267: 32-41. DOI: doi:10.1016/S0021-9797(03)00579-4.

[9] Dogan M, Alkan M. Some physicochemical properties of perlite as a adsorbent, Fresenius Environ. Bull. 2004 JAN; 13: 251-7.

[10] Alkan M, Dogan M. Surface titrations of perlite suspensions, J. Colloid Interface Sci. 1998 APR; 207: 90-6. DOI: $10.1006 /$ jcis.1998.5694.

[11] Tiwari A, Sen V. Dhakate SR, Mishra AP, Singh V. Synthesis, characterization, and hoping transport properties of $\mathrm{HCl}$ doped conducting biopolymer-co-polyaniline zwitterion hybrids. Polym. Advan. Technol. 2008 MAR; 19: 909-14. DOI: 10.1002/pat.1058.

[12] Li H, Yunling J, Shuzhen M, Fuhui L. Synthesis and electrorheological property of chitosan phosphate and its rare earth complex. Journal of Rare Earths. 2007 JUN; 25: 15-9. DOI: 10.1016/S1002-0721(07)60514-6.

[13] Marins, JA, Giulieri F, Soares BG, Bossis G. Hybrid polyaniline-coated sepiolite nanofibers for electrorheological fluid applications. Synth. Met. 2013 DEC; 185: 9-16. DOI: 10.1016/j.synthmet.2013.09.037.

[14] Cho MS, Choi HJ, Jhon MS. Shear stress analysis of a semiconducting polymer based electrorheological fluid system. Polymer. 2005; 46: 11484-8. DOI: 10.1016/j.polymer.2005.10.029.

[15] Cabuk M, Yavuz M, Unal HI, Erol O. Synthesis, characterization and investigation of electrorheological properties of biodegradable chitosan/bentonite nanocomposites. Clay Minerals. 2013 MAR; 48; 129-41. DOI: 10.1180/claymin.2013.048.4.09.

[16] Koyuncu K, Unal HI, Gumus OY, Erol O, Sari B, Ergin T. Electrokinetic and electrorheological properties of poly(vinyl chloride)/polyindole conducting composites, Polym. Advanc. Technol. 2011 OCT; 23: 1464-72. DOI: 10.1002/pat.2068. 


\section{Türkçe Öz ve Anahtar Kelimeler \\ Biyobozunur Kitosan/Genleşmiş Perlit Kompozitlerinin Elektroreolojik Özellikleri}

Öz: Bu çalışmada, kitosan (CS)/genleşmiş perlit (EP) kompozitleri farklı kitosan oranlarına (\%10, \%20 ve \%50) göre yeni bir hibrid akıllı elektroreolojik (ER) malzeme olarak, genleşmiş perlitin gözenekli ağ sistemi içine kitosanın adsorplanması ile hazırlandı. Kompozitlerin yapısal ve morfolojik karakterizasyonları FTIR ve SEM-EDS teknikleri ile gerçekleştirildi. Bunun dışında, CS/EP kompozitlerin görünür yoğunluğu, tanecik boyutu ve iletkenlikleri belirlendi. Son olarak, CS/EP/Silikon yağı (SO) sisteminin ER davranışı üzerine elektrik alan kuvveti (E), kayma hızı, kayma gerilimi ve sıcaklığın etkileri incelendi. CS/EP/SO ER sistemi E'ye maruz bırakıldığında kayma incelmesi türünden Newtoniyen olmayan viskoelastik davranış göstererek tersinir ER aktivite göstermiştir. CS/EP3 kompozitinin akma gerilimi değeri, $\mathrm{E}=3 \mathrm{kV} / \mathrm{mm}$ 'de 1250 Pa değerine ulaşmıştır.

Anahtar kelimeler: Elektroreolojik akışkanlar, genleşmiş perlit, kitosan, kompozit, silikon yağı, akma gerilimi.

Sunulma: 1 Temmuz 2016, Düzeltme: 15 Ağustos 2016, Kabul: 22 Ağustos 2016. 
